\title{
Brazilian Plasmodium falciparum isolates: investigation of candidate polymorphisms for artemisinin resistance before introduction of artemisinin-based combination therapy
}

\author{
Bianca E Gama', Natália K Almeida de Oliveira', José M de Souza², Fátima Santos ${ }^{3}$, Leonardo JM de Carvalho ${ }^{1,4}$, \\ Yonne FC Melo ${ }^{5}$, Philip J Rosenthal ${ }^{6}$, Cláudio T Daniel-Ribeiro ${ }^{1}$, Maria de Fátima Ferreira-da-Cruz ${ }^{1 *}$
}

\begin{abstract}
Background: This study was performed to better understand the genetic diversity of known polymorphisms in pfatpase6 and pfmdr1 genes before the introduction of ACT in Brazil, in order to get a genotypic snapshot of Plasmodium falciparum parasites that may be used as baseline reference for future studies.

Methods: Parasites from P. falciparum samples collected in 2002, 2004 and 2006-2007 were genotyped using PCR and DNA sequencing at codons 86, 130, 184, 1034, 1042, 1109 and 1246 for pfmdr1 gene, and 243, 263, 402, 431, $623,630,639,683,716,776,769$ and 771 for pfatpase6 gene.

Results: A pfmdr1 haplotype NEF/CDVY was found in $97 \%$ of the samples. In the case of pfatpase6, four haplotypes, wild-type (37\%), $630 \mathrm{~S}$ (35\%), $402 \mathrm{~V}(5 \%)$ and double-mutant $630 \mathrm{~S}+402 \mathrm{~V}(23 \%)$, were detected.

Conclusion: Although some polymorphism in pfmdr1 and pfatpase6 were verified, no reported haplotypes in both genes that may mediate altered response to ACT was detected before the introduction of this therapy in Brazil. Thus, the haplotypes herein described can be very useful as a baseline reference of $P$. falciparum populations without ACT drug pressure.
\end{abstract}

\section{Background}

Resistance to anti-malarial drugs is one of the major obstacles to effective malaria treatment and control. Due to the worldwide spread of Plasmodium falciparum resistant to chloroquine and sulphadoxine-pyrimethamine, the World Health Organization (WHO) recommends the use of artemisinin-based combination therapy (ACT) as first-line malaria treatment. Artemisinin and its derivatives rapidly reduce clinical symptoms and parasite burden. Combination with a second agent improves treatment outcomes and minimizes the possibility of selecting artemisinin-resistant parasites [1].

ACT has demonstrated outstanding anti-malarial efficacy, but its long-term promise has recently come into

\footnotetext{
* Correspondence: mffcruz@ioc.fiocruz.br

'Laboratory of Malaria Research, Instituto Oswaldo Cruz, Fiocruz, Rio de Janeiro (RJ), Brazil

Full list of author information is available at the end of the article
}

question. First, P. falciparum field isolates from French Guyana and Senegal with markedly reduced in vitro sensitivity to artemether were reported [2], although other reports from a number of areas have not replicated these results [3-5]. Second, recent reports from Cambodia identified parasites with slightly reduced in vitro sensitivity, but also showed significant prolongation of parasite clearance times after treatment with artesunate $[6,7]$. These results lead to concern that parasites with diminished sensitivity to artemisinins may be spreading around the world.

The mechanism of decreased susceptibility of malaria parasites to artemisinins is uncertain. Gene amplification or specific point mutations in codons $86,184,1034$, 1042 and 1246 of the $P$. falciparum multidrug resistance gene 1 (pfmdr1), have been associated with alterations in artemisinin sensitivity by genetic disruption, allelic replacement and in vitro experiments [8-11]. These
C Biomed Central

C 2010 Gama et al; licensee BioMed Central Ltd. This is an Open Access article distributed under the terms of the Creative Commons Attribution License (http://creativecommons.org/licenses/by/2.0), which permits unrestricted use, distribution, and reproduction in any medium, provided the original work is properly cited. 
polymorphisms also lead to diminished response to some other anti-malarials, including mefloquine and lumefantrine, and also enhanced response to chloroquine and amodiaquine $[8,12,13]$. There are also some indications for pfmdr1 in vivo allele selection [14-18], mainly N86, $184 \mathrm{~F}$ and D1246, in reinfecting parasites after artemether-lumefantrine (AL) treatment, a fact that may constitute a first step toward resistance [19].

A second gene in which polymorphisms may mediate alterations in artemisinin sensitivity is that encoding a SERCA-type calcium-translocating ATPase known as pfatpase6 [2], the only ATPase identified in the P. falciparum genome. However, this gene is more diverse than previously thought [20] and evidence of the roles of pfatpase6 mutations, specially that at codon S769N, in decreased in vitro sensitivity to artemisinins is uncertain [21].

To better understand this diversity and to get a genotypic snapshot baseline for future studies, known polymorphisms in pfatpase6 and pfmdr1 genes were assessed in $P$. falciparum parasites before the introduction of ACT in Brazil. At that time, treatment regimen recommended to falciparum malaria by Malaria National Control Program (MNCP) was quinine plus doxycycline or mefloquine. From 2007, Brazilian MNCP has been implementing ACT (artemether-lumefantrine and artesunate-mefloquine) as first-line regimen for uncomplicated falciparum malaria.

In Brazil, genotyping of $p f m d r 1$ gene is scarce and pfatpase6 analysis has just started. Two of such studies, conducted in 1998, evaluated polymorphisms on pfmdr1 gene $[22,23]$ and the recent investigation of pfatpase6 gene mutations was carried out with $P$. falciparum parasites from a single Pará state locality where only $14 \%$ of the isolates studied were DNA sequenced [4].

\section{Methods}

\section{Study sites, blood samples and DNA extraction}

Parasites from 119 P. falciparum blood samples were evaluated. These samples were collected in different periods, at the time of diagnosis of uncomplicated falciparum malaria patients living in three Brazilian endemic areas: Porto Velho, Rondônia state (2002; n = 46); Paragominas, Pará state (2004; $\mathrm{n}=19)$; and Manaus, Amazonas state (2006-2007; $\mathrm{n}=54)$. Irrespective the locality, the casuistic comprised male young adults (mean age 30 years) with 1900 parasites $/ \mu \mathrm{L}$ mean parasitaemia, that reported at least three previous malaria episodes. After obtaining informed consent, venous blood was collected according to protocols approved by the ethics research committees of Fiocruz, Fundação de Medicina Tropical do Amazonas, Instituto Evandro Chagas and Laboratory of Entomology. Pregnant women, indigenous people, prisoners and individuals less than 18 years of age were excluded. DNA was extracted from $1 \mathrm{ml}$ of cryopreserved blood using QIAamp midi columns as described by the manufacturer (Qiagen).

\section{Characterization of polymorphisms}

Relevant portions of the $p f m d r 1$ and pfatpase6 genes were amplified using primers as previously described to amplify N86Y, E130K, Y184F, S1034C, N1042 D, V1109I and D1246Y pfmdr1 SNPs [24] and H243Y, L263E, L402V, E431K, A623E, A630 S, G639 D, N683K, K716R, K776N, S769N plus K771E pfatpase6 SNPs [25]. PCR products were separated by $2 \%$ agarose-gel electrophoresis. Products were purified through the Wizard SV Gel and PCR Clean-Up System (Promega), according to the manufacturer's instructions. Amplified fragments were directly sequenced using Big Dye ${ }^{\odot}$ Terminator Cycle Sequencing Ready Reaction version 3.1 (Applied Biosystems) on an ABI PRISM DNA Analyzer 3730 (Applied Biosystems) from the Genomic Platform/ PDTIS/Fiocruz [26].

\section{Results}

Only isolates that were successfully amplified at all regions of a gene were considered. In this light, pfmdr1 polymorphisms were evaluable in 85 samples (19 for Paragominas, 33 for Porto Velho and 33 for Manaus localities) and pfatpase 6 polymorphisms in 65 samples (17 for Paragominas, 22 for Porto Velho and 26 for Manaus) for the most likely haplotype assembly. The amplification failures might have been due to primer sensitivity or to unexpected polymorphisms in target sequences, since all these samples generated DNA fragments using primers employed in malaria diagnosis based in conserved DNA regions [27]. Unsuccessfully PCR amplifications were already reported to $p f m d r 1$ gene [28] and in relation to pfatpase6 gene at least $25 \%$ of the samples did not have evaluable SNPs [29].

Analysis of $p f m d r 1$ gene revealed four single haplotypes. Three of these contained SNPs already associated with altered sensitivity to anti-malarial drugs (86Y, 184F, 1034C, $1042 \mathrm{D}$ and 1246Y). One pfmdr1 haplotype NEF/ CDVY (N86, E130, 184F, 1034C, 1042 D, V1109 and $1246 Y$ ) was present in $97 \%$ of samples. One parasite from Manaus displayed a wild type (3D7 strain) profile (Table 1). Concerning the pfatpase6 gene, four single haplotypes were found (HLLE/AAGNKKSK in 37\% of samples, HLLE/ASGNKKSK in 35\%, HLVE/AAGNKKSK in $5 \%$ and HLVE/ASGNKKSK in $23 \%$ of samples), displaying none, one (402 V or $630 \mathrm{~S})$ or two (402 V plus 630S) SNPs within the 12 positions analysed (H243Y, L263E, L402V, E431K, A623E, A630 S, G639 D, N683K, K716R, K776N, S769N and K771E). Mixed haplotypes were not seen in any samples.

A multilocus analysis was performed for 65 samples for which both pfmdr1 and pfatpase6 were evaluable. The 
Table 1 Pfmdr1 and pfatpase6 haplotypes from Paragominas (PRG), Porto Velho (PV) and Manaus (MAN) isolates.

\begin{tabular}{|c|c|c|c|c|}
\hline Gene & Haplotypes & n (n/locality) & $\%$ & $\begin{array}{l}\text { Mutated } \\
\text { codons }\end{array}$ \\
\hline \multirow[t]{4}{*}{$\begin{array}{l}\text { pfmdr1 } \\
(\mathrm{n}=85)\end{array}$} & NEF/CD $\vee Y$ & $\begin{array}{l}82 \text { (19/PRG, 33/PV, 30/ } \\
\text { MAN) }\end{array}$ & 97 & 4 \\
\hline & NEF/SD $\vee Y$ & 1 (MAN) & 1 & 3 \\
\hline & YEY/SNVD & 1 (MAN) & 1 & 1 \\
\hline & NEY/SNVD & 1 (MAN) & 1 & 0 \\
\hline \multirow[t]{4}{*}{$\begin{array}{l}\text { pfatpase6 } \\
(\mathrm{n}=65)\end{array}$} & $\frac{\text { HLLE/ }}{\text { AAGNKKSK }}$ & $\begin{array}{l}24(6 / P R G, 4 / P V, 14 / \\
\text { MAN) }\end{array}$ & 37 & 0 \\
\hline & $\begin{array}{l}\text { HLLE/ } \\
\text { ASGNKKSK }\end{array}$ & $23(11 / P R G, 12 / M A N)$ & 35 & 1 \\
\hline & $\begin{array}{l}\text { HLVE/ } \\
\text { AAGNKKSK }\end{array}$ & $3(\mathrm{PV})$ & 5 & 1 \\
\hline & $\begin{array}{l}\text { HLVE/ } \\
\text { ASGNKKSK }\end{array}$ & $15(\mathrm{PV})$ & 23 & 2 \\
\hline
\end{tabular}

Codon positions: pfmdr1 N86Y, E130K, Y184F, S1034C, N1042 D, V1109l, D1246Y ( $n=85$ ); pftapase6 H243Y, L263E, L402V, E431K, A623E, A630 S, G639 D, N683K, K716R, K776N, S769N, K771E ( $n=65)$. The haplotype of 3D7 strain is underlined and the mutated codons are shown in bold characters.

associations found were (see Table 1 for description of haplotypes): NEF/CDVY + HLLE/ASGNKKSK (41\%), NEF/CDVY + HLLE/AAGNKKSK (31\%), NEF/ CDVY + HLVE/ASGNKKSK (25\%), NEF/CDVY + HLVE/AAGNKKSK (1.5\%) and YEY/SNVD + HLLE/ AAGNKKSK (1.5\%).

Of the three studied localities, Paragominas and Porto Velho displayed only one $p f m d r 1$ haplotype (NEF/ CDVY), in contrast to Manaus, which presented some allelic variation (NEF/CDVY, NEY/SNVD, YEY/SNVD and NEF/SDVY). However, even in Manaus, NEF/CDVY was by far the most prevalent haplotype (91\%). For pfatpase6, HLLE/ASGNKKSK was predominant in Paragominas (65\%), HLVE/ASGNKKSK in Porto Velho (68\%), and HLLE/AAGNKKSK and HLLE/ASGNKKSK haplotypes in Manaus (54\% and 46\%, respectively).

\section{Discussion}

It was assessed mutations in two genes of $P$. falciparum parasites that have previously been implicated in mediating resistance to artemisinin and other anti-malarial drugs, from Rondônia, Pará and Amazonas states in Brazil. It was found a range of polymorphisms in both pfmdr1 and pfatpase6, although pfmdr1 gene was more polymorphic than pfatpase6 one.

Regarding $p f m d r 1$, the majority of isolates from all sites displayed the NEF/CDVY allele that was first described in 1998 in P. falciparum isolates from Mato Grosso and Amapá states $[22,23]$. The NEF/CDVY haplotype might have been selected by extensive use of quinine in Brazil, as suggested by a reverse genetics experiment in which mutations $1034 \mathrm{C}+1042 \mathrm{D}+1246 \mathrm{Y}$ were associated with decreased sensitivity to quinine [12]. In Manaus city, another haplotype, YEY/SNVD, was seen in one sample. This haplotype has previously been reported in Colombia and Guyana [30,31], but not in Brazil. The set of pfmdr1 haplotypes herein identified did not include the combination of N86, 184F and D1246 codons, already reported in patients with recurrent parasitaemia after AL treatment [14-18].

For pfatpase6 a few polymorphisms were detected as already observed in another Pará state locality [4], contrasting to those reported in Africa [15]. Importantly, the $\mathrm{S} 769 \mathrm{~N}$ mutation, which was previously reported to associate with decreased in vitro response to artemether in French Guiana, was not seen. In 35\% of the isolates, only one SNP (630S) was detected in parasites from Paragominas and Manaus, and double-mutant parasites $(402 \mathrm{~V}+630 \mathrm{~S})$ were noticed in $23 \%$ of the isolates, in parasites from Porto Velho. The $402 \mathrm{~V}$ and $630 \mathrm{~S}$ mutations have also been detected in P. falciparum parasites from Africa [20,25,32] and elsewhere [33], but they were not observed in another study of Brazilian isolates from Tucuruí city, Pará state [4]. It is noteworthy that parasites from Paragominas, a rural and isolated locality, had the $630 \mathrm{~S}$ mutation, demonstrating that polymorphisms have a broad geographical range.

After an initial report linking a pfatpase6 polymorphism with altered response to artemether [2], the association between pfatpase6 SNPs and artemisinin response has been uncertain. Recent in vivo reports did not find associations between altered artemisinin responses and pfatpase6 polymorphisms $[6,7,34]$. Further, parasites selected for artemisinin tolerance did not contain pfatpase6 SNPs previously associated with altered artemisinin response [35]. Thus, the role of pfatpase6 polymorphisms is uncertain, but in any event a range of polymorphisms in both this gene and in pfmdr1 was observed in Brazil.

\section{Conclusions}

In this study, although some polymorphism in pfmdr1 and pfatpase6 were verified, no reported haplotypes in both genes that may mediate altered response to ACT were detected before the introduction of this therapy in Brazil. Thus, the haplotypes herein described can be very useful as baseline reference of $P$. falciparum populations without ACT drug pressure.

\section{Acknowledgements}

We are sincerely grateful to Paulo Renato Rivas Totino, Evelyn Kety Pratt Riccio, Lilian Rose Pratt Riccio and Clarissa Perez Faria, who generously provided blood samples for this study and to all patients that kindly donated blood samples. We are also indebted to the staff of the Genomic Platform/PDTIS/Fiocruz. Leonardo JM de Carvalho is recipient of $\mathrm{NIH}$ grants R01-HL87290 and R01-Al082610. This work was supported by POM/PEF/ Instituto Oswaldo Cruz, PAPES-Fiocruz, and CNPq-PRONEX/DECIT/FAPERJ programs (Brazil) 


\section{Author details}

'Laboratory of Malaria Research, Instituto Oswaldo Cruz, Fiocruz, Rio de Janeiro (RJ), Brazil. ${ }^{2}$ Ambulatory and Laboratory of Malaria Clinical Assays, Secretariat of Health Vigilance, Instituto Evandro Chagas, Belém (PA), Brazil. ${ }^{3}$ Laboratory of Entomology, LACEN, Porto Velho (RO), Brazil. ${ }^{4}$ La Jolla Bioengineering Institute, California, USA. ${ }^{5}$ Fundação de Medicina Tropical do Amazonas, Manaus (AM), Brazil. ${ }^{6}$ Department of Medicine, San Francisco General Hospital, University of California, San Francisco, USA.

\section{Authors' contributions}

BEG participated in the design of the study, carried out the molecular analysis and drafted the manuscript; NKAO performed the PCR assays; JMS, FS and YFCM helped in design of the study and field facilities for blood sample collections; LJMC, PJR and CTDR helped in the design of the study and reviewed the manuscript; MFFC conceived the study, coordinated its design, and finalized the manuscript. All authors have read and approved the final text.

\section{Competing interests}

The authors declare that they have no competing interests.

Received: 20 October 2010 Accepted: 8 December 2010

Published: 8 December 2010

\section{References}

1. Sinclair D, Zani B, Donegan S, Olliaro P, Garner P: Artemisinin-based combination therapy for treating uncomplicated malaria. Cochrane Database Syst Rev 2009, 3:CD007483.

2. Jambou R, Legrand E, Niang M, Khim N, Lim P, Volney B, Ekala M, Bouchier C, Esterre P, Fandeur T, Mercereau-Puijalon O: Resistance of Plasmodium falciparum field isolates to in-vitro artemether and point mutations of the SERCA-type PfATPase6. Lancet 2005, 366:1960-1963.

3. Ferreira I, Lopes D, Martinelli A, Ferreira C, do Rosário V, Cravo P: In vitro assessment of artesunate, artemether and amodiaquine susceptibility and molecular analysis of putative resistance-associated mutations of Plasmodium falciparum from São Tomé and Príncipe. Trop Med Int Health 2007, 12:353-362.

4. Ferreira I, Martinelli A, Rodrigues L, do Carmo E, do Rosário V, Póvoa M, Cravo P: Plasmodium falciparum from Pará state (Brazil) shows satisfactory in vitro response to artemisinin derivatives and absence of the S769N mutation in the SERCA-type PfATPase6. Trop Med Int Health 2008, 13:199-207.

5. Tahar R, Ringwald P, Basco L: Molecular epidemiology of malaria in Cameroon. XXVIII. In vitro activity of dihydroartemisinin against clinical isolates of Plasmodium falciparum and sequence analysis of the $P$. falciparum ATPase 6 gene. Am J Trop Med Hyg 2009, 81:13-18.

6. Noedl H, Se Y, Schaecher K, Smith B, Socheat D, Fukuda M: Evidence of artemisinin-resistant malaria in western Cambodia. N Engl J Med 2008, 359:2619-2620.

7. Dondorp A, Nosten F, Yi P, Das D, Phyo A, Tarning J, Lwin K, Ariey F, Hanpithakpong W, Lee SJ, Ringwald P, Silamut K, Imwong M, Chotivanich K, Lim P, Herdman T, An SS, Yeung S, Singhasivanon P, Day NP, Lindegardh N, Socheat $\mathrm{D}$, White NJ: Artemisinin resistance in Plasmodium falciparum malaria. N Engl I Med 2009, 361:455-467.

8. Reed M, Saliba K, Caruana S, Kirk K, Cowman A: Pgh1 modulates sensitivity and resistance to multiple antimalarials in Plasmodium falciparum. Nature 2000, 403:906-909.

9. Meshnick S: Artemisinin: mechanisms of action, resistance and toxicity. Int J Parasitol 2002, 32:1655-1660.

10. Duraisingh $M$, Jones $P$, Sambou I, von Seidlein L, Pinder M, Warhurst D: The tyrosine-86 allele of the pfmdr1 gene of Plasmodium falciparum is associated with increased sensitivity to the anti-malarials mefloquine and artemisinin. Mol Biochem Parasitol 2000, 108:13-23.

11. Sidhu A, Uhlemann A, Valderramos S, Valderramos J, Krishna S, Fidock D: Decreasing pfmdr1 copy number in Plasmodium falciparum malaria heightens susceptibility to mefloquine, lumefantrine, halofantrine, quinine, and artemisinin. J Infect Dis 2006, 194:528-535.

12. Sidhu A, Valderramos S, Fidock D: pfmdr1 mutations contribute to quinine resistance and enhance mefloquine and artemisinin sensitivity in Plasmodium falciparum. Mol Microbiol 2005, 57:913-926.
13. Pickard A, Wongsrichanalai C, Purfield A, Kamwendo D, Emery K, Zalewski C, Kawamoto F, Miller R, Meshnick S: Resistance to antimalarials in Southeast Asia and genetic polymorphisms in pfmdr1. Antimicrob Agents Chemother 2003, 47:2418-2423.

14. Sisowath C, Strömberg J, Mårtensson A, Msellem M, Obondo C, Björkman A, Gil J: In vivo selection of Plasmodium falciparum pfmdr $186 \mathrm{~N}$ coding alleles by artemether-lumefantrine (Coartem). J Infect Dis 2005, 191:1014-1017.

15. Sisowath $C$, Ferreira $P$, Bustamante $L$, Dahlström $S$, Mårtensson $A$, Björkman A, Krishna S, Gil J: The role of pfmdr1 in Plasmodium falciparum tolerance to artemether-lumefantrine in Africa. Trop Med Int Health 2007, 12:736-742.

16. Happi C, Gbotosho G, Folarin O, Sowunmi A, Hudson T, O'Neil M, Milhous W, Wirth D, Oduola A: Selection of Plasmodium falciparum multidrug resistance gene 1 alleles in asexual stages and gametocytes by artemether-lumefantrine in Nigerian children with uncomplicated falciparum malaria. Antimicrob Agents Chemother 2009, 53:888-895.

17. Dokomajilar C, Nsobya S, Greenhouse B, Rosenthal P, Dorsey G: Selection of Plasmodium falciparum pfmdr1 alleles following therapy with artemether-lumefantrine in an area of Uganda where malaria is highly endemic. Antimicrob Agents Chemother 2006, 50:1893-1895.

18. Humphreys G, Merinopoulos I, Ahmed J, Whitty C, Mutabingwa T, Sutherland C, Hallett R: Amodiaquine and artemether-lumefantrine select distinct alleles of the Plasmodium falciparum mdr1 gene in Tanzanian children treated for uncomplicated malaria. Antimicrob Agents Chemother 2007, 51:991-997.

19. Sisowath C, Petersen I, Veiga M, Mårtensson A, Premji Z, Biörkman A, Fidock D, Gil J: In vivo selection of Plasmodium falciparum parasites carrying the chloroquine-susceptible pfcrt K76 allele after treatment with artemether-lumefantrine in Africa. J Infect Dis 2009, 199:750-757.

20. Dahlström S, Veiga M, Ferreira $P$, Mårtensson A, Kaneko A, Andersson B, Björkman A, Gil J: Diversity of the sarco/endoplasmic reticulum $\mathrm{Ca}(2$ +)-ATPase orthologue of Plasmodium falciparum (PfATP6). Infect Genet Evol 2008, 8:340-345.

21. Egan T: Artemisinin-resistant Plasmodium falciparum: can the genie be put back in the bottle? Future Microbiol 2009, 4:637-639.

22. Zalis M, Pang L, Silveira M, Milhous W, Wirth D: Characterization of Plasmodium falciparum isolated from the Amazon region of Brazil: evidence for quinine resistance. Am J Trop Med Hyg 1998, 58:630-637.

23. Póvoa M, Adagu I, Oliveira S, Machado R, Miles M, Warhurst D: Pfmdr 1 Asn1042Asp and Asp1246Tyr polymorphisms, thought to be associated with chloroquine resistance, are present in chloroquine-resistant and -sensitive Brazilian field isolates of Plasmodium falciparum. Exp Parasitol 1998, 88:64-68.

24. Gama B, Pereira-Carvalho G, Lutucuta Kosi F, Almeida de Oliveira N, Fortes F, Rosenthal P, Daniel-Ribeiro C, Ferreira-da-Cruz MF: Plasmodium falciparum isolates from Angola show the StctVMNT haplotype in the pfcrt gene. Malar J 2010, 9:174

25. Menegon M, Sannella A, Majori G, Severini C: Detection of novel point mutations in the Plasmodium falciparum ATPase6 candidate gene for resistance to artemisinins. Parasitol Int 2008, 57:233-235.

26. Otto T, Vasconcellos E, Gomes L, Moreira A, Degrave W, Mendonça-Lima L, Alves-Ferreira M: ChromaPipe: a pipeline for analysis, quality control and management for a DNA sequencing facility. Genet Mol Res 2008, 7:861-871

27. Zalis M, Ferreira-da-Cruz M, Balthazar-Guedes $H$, Banic $D$, Alecrim $W$ Souza J, Druilhe P, Daniel-Ribeiro C: Malaria diagnosis: standardization of a polymerase chain reaction for the detection of Plasmodium falciparum parasites in individuals with low-grade parasitemia. Parasitol Res 1996, 82:612-616.

28. Uhlemann A, McGready R, Ashley E, Brockman A, Singhasivanon $P$, Krishna S, White N, Nosten F, Price R: Intrahost selection of Plasmodium falciparum pfmdr1 alleles after antimalarial treatment on the northwestern border of Thailand. J Infect Dis 2007, 195:134-141.

29. Mugittu K, Genton B, Mshinda H, Beck H: Molecular monitoring of Plasmodium falciparum resistance to artemisinin in Tanzania. Malar J 2006, 5:126.

30. Echeverry D, Holmgren G, Murillo C, Higuita J, Björkman A, Gil J, Osorio L: Short report: polymorphisms in the pfcrt and pfmdr1 genes of Plasmodium falciparum and in vitro susceptibility to amodiaquine and desethylamodiaquine. Am J Trop Med Hyg 2007, 77:1034-1038. 
31. Mehlotra R, Mattera G, Bockarie M, Maguire J, Baird J, Sharma Y, Alifrangis M, Dorsey G, Rosenthal P, Fryauff D, Kazura JW, Stoneking M, Zimmerman PA: Discordant patterns of genetic variation at two chloroquine resistance loci in worldwide populations of the malaria parasite Plasmodium falciparum. Antimicrob Agents Chemother 2008, 52:2212-2222.

32. Ibrahim M, Khim N, Adam H, Ariey F, Duchemin J: Polymorphism of PfATPase in Niger: detection of three new point mutations. Malar J 2009, 8:28.

33. Jambou R, Martinelli A, Pinto J, Gribaldo S, Legrand E, Niang M, Kim N, Pharath L, Volnay B, Ekala M, Bouchier C, Fandeur T, Berzosa P, Benito A, Ferreira ID, Ferreira C, Vieira PP, Alecrim MG, Mercereau-Puijalon O, Cravo P: Geographic structuring of the Plasmodium falciparum sarco(endo) plasmic reticulum Ca2+ ATPase (PFSERCA) gene diversity. PLoS One 2010, 5:e9424.

34. Imwong M, Dondorp A, Nosten F, Yi P, Mungthin M, Hanchana S, Das D, Phyo A, Lwin K, Pukrittayakamee S, Lee SJ, Saisung S, Koecharoen K, Nguon C, Day NP, Socheat D, White NJ: Exploring the contribution of candidate genes to artemisinin resistance in Plasmodium falciparum. Antimicrob Agents Chemother 2010, 54:2886-2892.

35. Witkowski B, Lelièvre J, Barragán M, Laurent V, Su X, Berry A, Benoit-Vical F: Increased tolerance to artemisinin in Plasmodium falciparum is mediated by a quiescence mechanism. Antimicrob Agents Chemother 2010 54:1872-1877.

\section{doi:10.1186/1475-2875-9-355}

Cite this article as: Gama et al: Brazilian Plasmodium falciparum isolates: investigation of candidate polymorphisms for artemisinin resistance before introduction of artemisinin-based combination therapy. Malaria Journal 2010 9:355.

\section{Submit your next manuscript to BioMed Central and take full advantage of:}

- Convenient online submission

- Thorough peer review

- No space constraints or color figure charges

- Immediate publication on acceptance

- Inclusion in PubMed, CAS, Scopus and Google Scholar

- Research which is freely available for redistribution

Submit your manuscript at www.biomedcentral.com/submit 